TABLE II. - Position of the bands at liquid nitrogen temperature, comparison with calalated values (er).

\begin{tabular}{|c|c|c|c|c|c|c|}
\hline & $\begin{array}{l}h v_{\text {ire }} \\
\text { Th. }\end{array}$ & $-h v_{\beta}$ & $v_{\text {free }}$ & $\frac{-7 v}{\operatorname{Exp}}$ & $h_{\beta}$ & $h v_{\alpha}$ \\
\hline 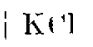 & .28 & $.3 \mathbf{1}$ & .53 & (76 & .25 & .45 \\
\hline k & .29 & .35 & .49 & .63 & .21 & .28 \\
\hline & .23 & .32 & .44 & .59 & .21 & 27 \\
\hline $\mathrm{NaCl}$ & .19 & .69 & .50 & .85 & .31 & .26 \\
\hline
\end{tabular}

\footnotetext{
$h v_{\text {free }}=$ energy of first exciton peak, experiniental values from ref. (").

Experimental values for $h v_{\alpha}$ and $h v_{\beta}$ from ref. $\left({ }^{12}\right)$, and the present work.

All theoretical values from ref. $\left(^{5}\right)$. The expcrimental values for $\mathrm{KBr}$ given in ref. ${ }^{5}$ ) differ from those above due to the recent measurement of $h v_{\text {iree }}$.
}

the potassium salts and that the $x$ bands occur at considerably lower energies than were predicted.

Frchs (7) has computed the oscillator strength and autoionization lifetime of the $\beta$ band in Narl. He found that the $\beta$ band should consist of six components, four of which are probably well into the fundamental absorption band and are unobservable. The other two should be

(') I. Frine: Phys. Rev., 111, 387 (1958). separated by $0.10 \mathrm{eV}$, giving rise to a doublet $\beta$ band. Since this splitting is a result of the spin-orbit coupling of the hole distributed on the $\mathrm{Cl}^{-}$ions nearest the $F$-center, a similar result is expected in $\mathrm{KCl}$. A splitting of the $\beta$ band is not observed in the curves of Fig. 1 and 2, although a loublet is seen for exciton production in perfect erystals $\left(^{(6,8}\right)$. Measurements at lower temperatures may clarify this rather obscure point.

One of the authors (D.W.I.) wishes to express appreciation to the Commissione Americana per gli Scambi Culturali con l'Italia for a student Fulbright grant.

\section{Note added in proof.}

Since our work was sent to the publisher, R. Ošaka and I. FUJITA announced the publication in the Phys. Rev. of a paper on the same subject. (Abstract appeared in Phys. Rev. Lett., 5, 29 (1960)). We thank Prof. R. ONAKA for having sent us a copy of his work prior to publication.

$\left.{ }^{8}\right)$ P. L. HaRTMax, J. R. Netson and J. S. SIEGFRIFN: Phys. Rev., 105, 123 (1957).

\title{
Effect of Lepton Non-Conservation on $\pi$-Decay.
}

\author{
P. K. KABIR \\ Saha Institute of Nuclear Physics - University of Catcutta \\ (Nuoro Cimento, 17, $438(1960))$
}

The principal result (4) and conclusion of this paper are incorrect; the factors $m_{\pi}^{2} / m_{\text {s }}^{2}$ and $m_{\pi}^{2} / m_{\mu}^{2}$ should not be present. For equal muon and electron coupling constants, the branching ratio is unaltered from the Ruderman-Finkelstein value, consequently no conclusion can be drawn about lepton conservation. 